\title{
The Regional Warning Center Darmstadt (from the 1960s until 1993)
}

\author{
Thomas Damboldt ${ }^{1, \dagger}$ \\ ${ }^{1}$ Arheilger Woogstr. 65, 64291 Darmstadt, Germany \\ $\dagger$ deceased, 30 March 2015 \\ Correspondence: Kristian Schlegel (kristian.schlegel@coperinus.org) \\ Published: 12 April 2018
}

\begin{abstract}
The work and achievements of the Regional Warning Center Darmstadt at the Research Institute of the Deutsche Bundespost in Darmstadt, Germany, are briefly reviewed. After privatisation of the Deutsche Bundespost (now Deutsche Telekom) in 1993, research in HF propagation and hence the RWC was disbanded.
\end{abstract}

\section{Work and achievements of the RWC Darmstadt}

It is not clear when the RWC Darmstadt was established. The corresponding Research Group FI33 (later FI34) was located at the Research Institute of the Deutsche Bundespost within the Fernmeldetechnisches Zentralamt (Central Office for Telecommunication) Darmstadt. In the 1960s geophysical data were collected from other RWCs, from the ionosonde of the Max-Planck-Institut für Aeronomie at Lindau/Harz (Dieminger, 1972) and from the German Geophysical Observatory at Wingst (Schmucker, 1988) by 50-baud teletype. In addition, large amounts of data came in from other RWCs. In fact, during the weekends the amount of data exceeded the capacity of the normal-sized punched tape reels, and we specially ordered double-sized tapes which were attached on extra large reels. Our own measurements of HF propagation began before 1965 near Detmold $\left(51^{\circ} 52^{\prime} \mathrm{N}\right.$, $\left.8^{\circ} 56^{\prime} \mathrm{E}\right)$ and moved to Lüchow (52 $\left.57^{\prime} \mathrm{N}, 11^{\circ} 13^{\prime} \mathrm{E}\right)$ in 1966. A number of ladies listened to distant radio stations and noted the hourly signal strength on paper sheets under the direction of Peter Süßmann. A 4-day variation in our measured signal strength data was found later on and was traced to the work shift, as there were always the same people doing the 4-day shift. A 7-day trend was also observed which was found to be due to not all transmitters transmitting during the weekends. The data were sent daily from Lüchow to Darmstadt. The head of the ionospheric group and the RWC at Darmstadt was Bruno Beckmann (1903-1981) with Alfred Ochs as deputy. From 1968 on, the observation of HF propagation conditions was automated step by step by recording the
AGC voltages of the receivers on paper charts. In 1971 Peter Süßmann was transferred to Darmstadt and the recordings of the measurements were relayed in real time to Darmstadt by dedicated telephone lines. After the retirement of Bruno Beckmann, Thomas Damboldt took over in 1974 until the closure of the RWC in 1993.

The AGC voltages of the receivers at Lüchow (and from 1980 at Norddeich, $53^{\circ} 34^{\prime} \mathrm{N}, 7^{\circ} 06^{\prime} \mathrm{E}$ ) were digitised and the paper chart recorders at Darmstadt were manually evaluated in the early morning. We chose mainly weather fax transmissions from coastal radio stations because they were transmitted in F1 modulation (frequency shift keying, Anderson, 2005). They transmitted one frequency for black and one for white colour. Using narrow IF filters in the receivers enabled us to chose only one of the two signals transmitted. There were mostly three to five frequencies simultaneously "on the air" from the same station (we called it circuit) using the same transmitted information. By comparing the recorded signal shape, i.e. on and off periods should appear at the same time, it was possible to distinguish between the "real signal" and interference. In those years the signal strength of up to 26 radio stations from up to six circuits was monitored (see Fig. 1) and the manually evaluated hourly median signalstrength values were typed into the computer. From the measured signal strength, the "radio propagation quality figure" was calculated for each circuit, ranging from 0 to 14 , where 6 was considered "normal". The quality figures were drawn daily in terms of solar rotations in order to see the recurrence tendency immediately (Fig. 2). An URSI code called 


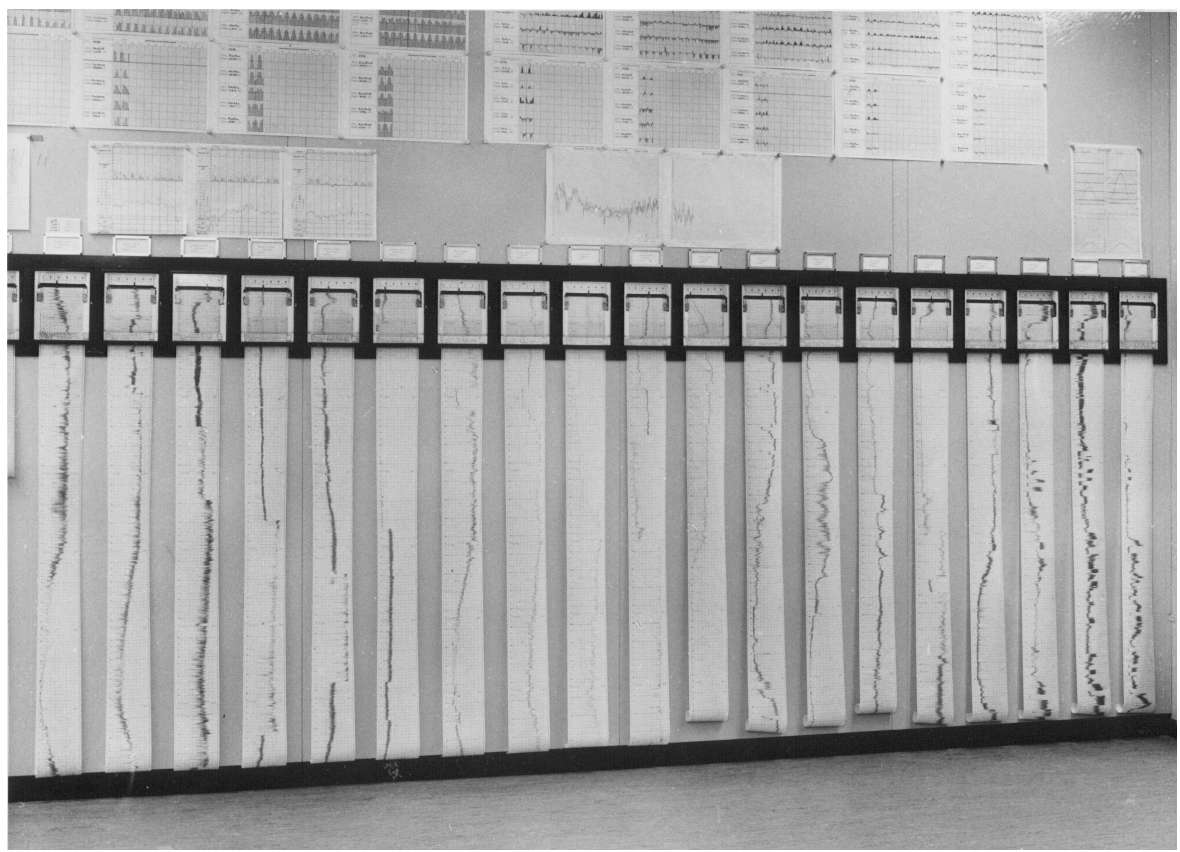

Figure 1. The signal strength of up to 26 distant transmitters was recorded in real time at RWC Darmstadt.
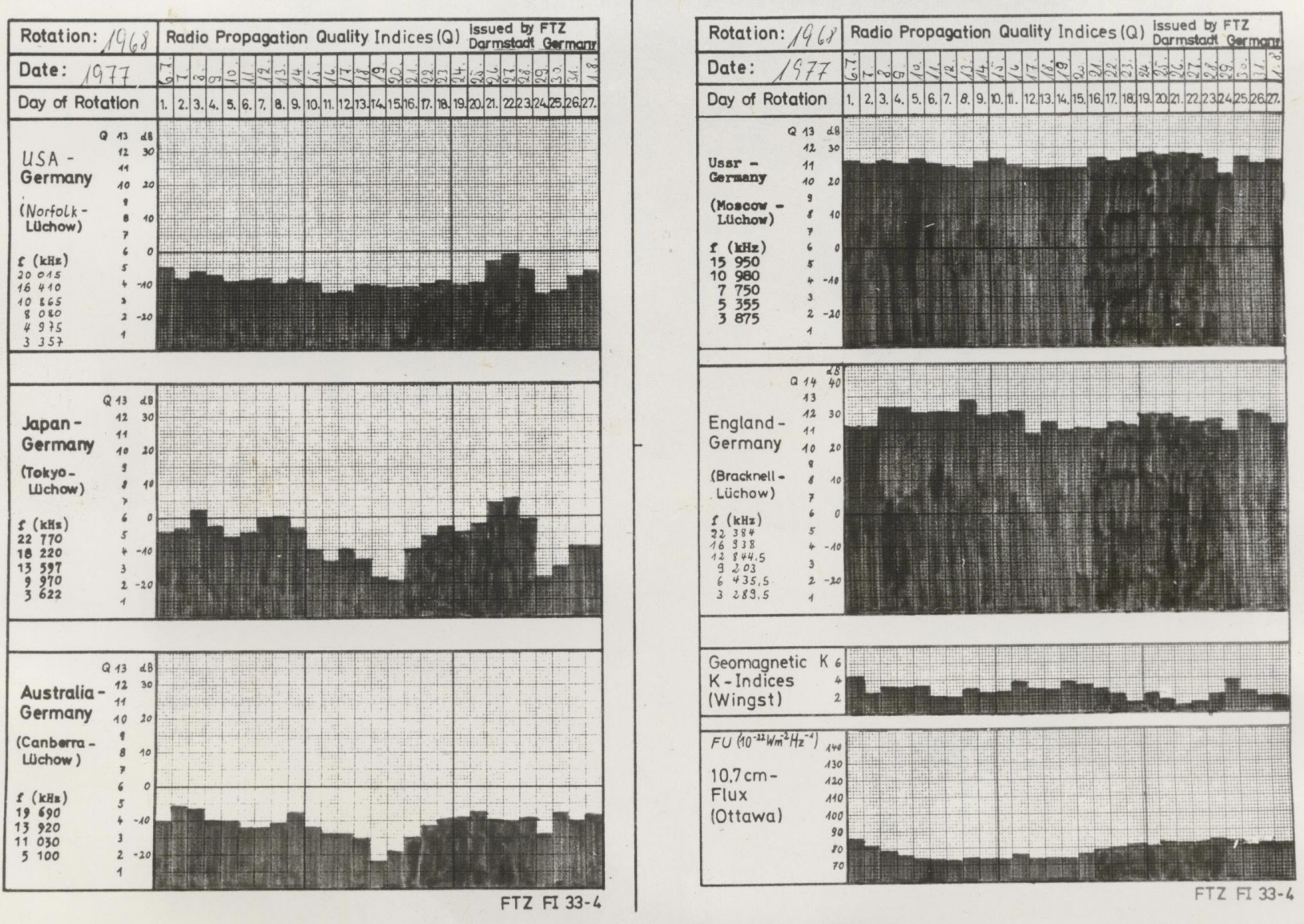

Figure 2. For each circuit, daily “Quality Indices” were calculated and arranged in solar rotations. 


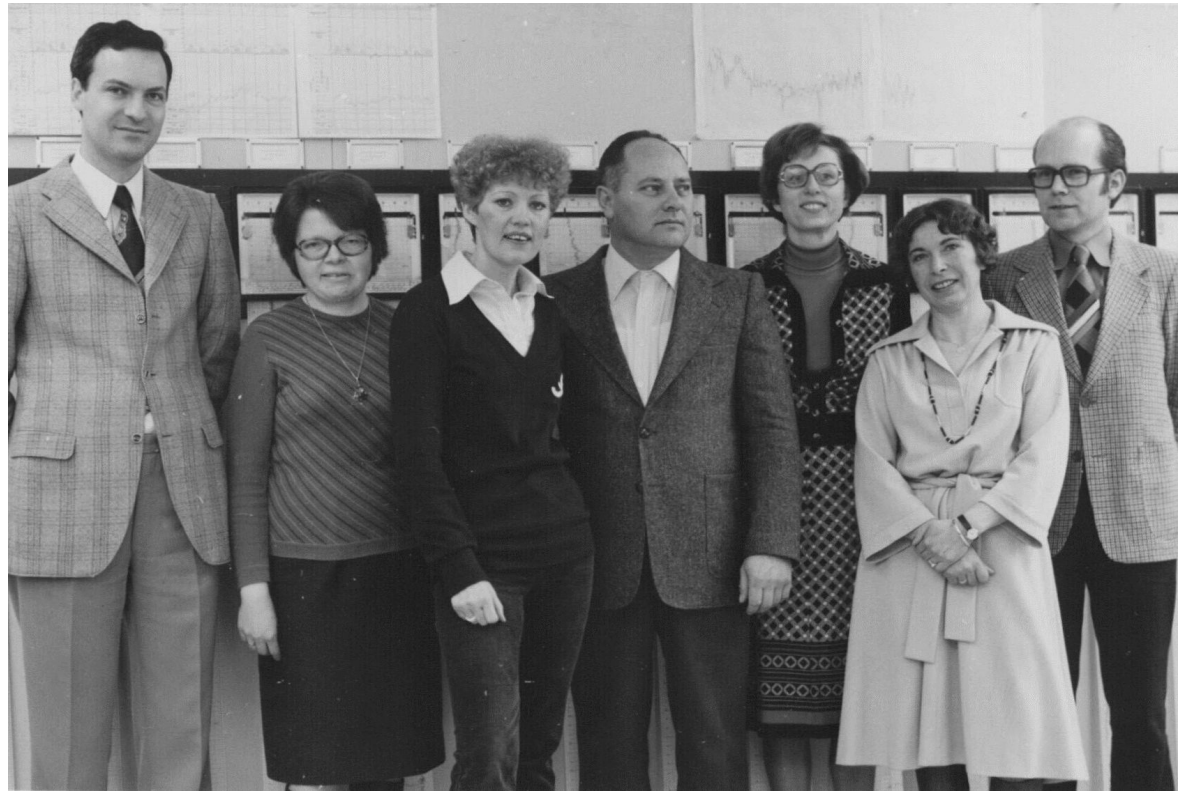

Figure 3. RWC Darmstadt in 1978: from left, Thomas Damboldt, Helga Landvogt, Doris Sperlich, Wilfried Foeks, Ingrid Hohmann, Liddy Schwarz, and Peter Süßmann.

UPROP was created for the radio propagation quality figure and the values were distributed through the URSIGRAM system regularly. A description of this code can still be found at http://www.spaceweather.org/ISES/code/rs/uprop.html.

In addition, shortwave fadeouts were reported, as they could be seen on the recordings in real time. Data received through the teletype machines as well as our own data were displayed in graphics on the walls in the office (see Fig. 1). With all this information we had a good overview of the geophysical situation and produced our "Daily report" on HF propagation every weekday at about 08:00. All values were also distributed through the URSIGRAM service and to a number of domestic interested parties (Coastal Radio Station Norddeich, Foreign Ministry, Ministry of the Interior, Monitoring Services and Ministry of Defense).

From 1983 until 1992 we ran our own ionosonde at St. Peter Ording in northern Germany $\left(54^{\circ} 18^{\prime} \mathrm{N}, 8^{\circ} 36^{\prime} \mathrm{E}\right)$ and the data were relayed once per day to RWC Darmstadt and fed into the URSIGRAM service. The data are still available at the World Data Center on CD (Digital Database, 19571990).

Figure 3 shows the personnel at RWC Darmstadt in 1978. It was with great sadness that we had to close down all measurements as well as the RWC on 31 December 1993.

Data availability. Our field-strength measurements, about 1.6 million hourly median values are still available at the ITU Archive in Geneva (www.itu.int/en/ITU-R/study-groups/rsg3/ Pages/iono-tropo-spheric.aspx; ITU, 2018).
Special issue statement. This article is part of the special issue "History of regional warning centers". It is not associated with a conference.

Acknowledgements. The editors thank Peter Süßmann for valuable comments and additions.

Edited by: Kristian Schlegel

\section{References}

Anderson, J. B.: Digital Transmission Engineering, 2nd Edn., 126127, Wiley Interscience, Chichester, UK, 2005.

Dieminger, W.: Aus der Geschichte des MPI für Aeronomie, in: Max-Planck-Institut für Aeronomie, Institut für Ionosphärenphysik, Festschrift zum 25 jährigen Bestehen des Instituts für Ionosphärenphysik in Lindau am Harz 1946-1971, 10-23, Lindau, Germany, 1972.

Digital Database: National Geophysical Data Center (E/GC2), WDC-A for Solar Terrestrial Physics, Boulder, USA, 19571990.

ITU: Software, Data and Validation examples for ionospheric and tropospheric radio wave propagation and radio noise, available at: www.itu.int/en/ITU-R/study-groups/rsg3/Pages/ iono-tropo-spheric.aspx, last access: 9 April 2018.

Schmucker, U.: The Wingst Geomagnetic Observatory and the Development of Geomagnetism during the past 50 years, Dt. hydrogr. Zeitschr., 41, 93-107, 1988. 